\title{
Electron Transfer Rate Maxima at Large Donor-Acceptor Distances
}

\author{
Martin Kuss-Petermann and Oliver S. Wenger* \\ Department of Chemistry, University of Basel, St. Johanns-Ring 19, 4056 Basel, Switzerland
}

\section{Supporting Information}

ABSTRACT: Because of their low mass, electrons can transfer rapidly over long (>15 ̊̊) distances, but usually reaction rates decrease with increasing donor-acceptor distance. We report here on electron transfer rate maxima at donor-acceptor separations of $30.6 \AA$, observed for thermal electron transfer between an anthraquinone radical anion and a triarylamine radical cation in three homologous series of rigidrod-like donor-photosensitizer-acceptor triads with $p$-xylene bridges. Our experimental observations can be explained by a weak distance dependence of electronic donor-acceptor

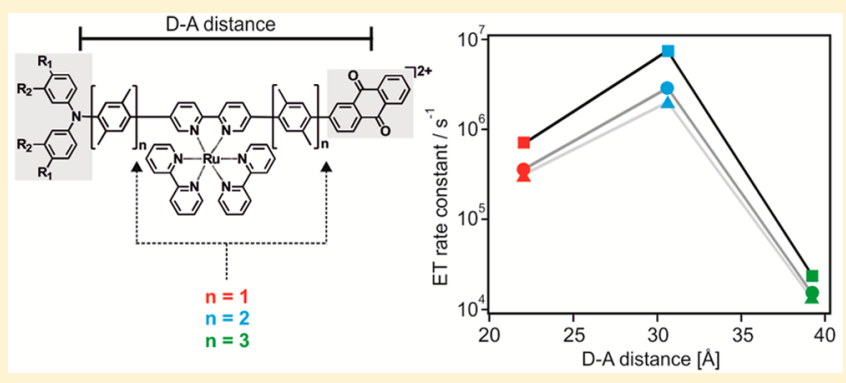
coupling combined with a strong increase of the (outersphere) reorganization energy with increasing distance, as predicted by electron transfer theory more than 30 years ago. The observed effect has important consequences for light-to-chemical energy conversion.

\section{INTRODUCTION}

The distance dependence of electron transfer rates has been investigated rather thoroughly over the past few decades, ${ }^{1}$ yet there are still important discoveries to be made as it turns out. Much attention has been devoted to tunneling and hopping mechanisms in proteins or $\mathrm{DNA}^{1 \mathrm{n}, \mathrm{o}, 2}$ and to the development of artificial molecular wires that mediate long-range electron transfer with shallow distance dependences. ${ }^{1 k, 3}$ Experimental insights have fostered advances in theoretical understanding and vice versa. ${ }^{4}$ Commonly, electron transfer rates decrease with increasing distance between a donor and an acceptor, ${ }^{5}$ but theory predicts a regime in which the rate for electron transfer increases with increasing donor-acceptor separation. ${ }^{6}$ We recently communicated a series of three rigid-rod-like donorphotosensitizer-acceptor triads in which we observed this unusual effect. ${ }^{7}$ In this paper we give a more detailed account for which we have extended our studies to three different series of triads.

In the semiclassical limit, electron transfer rates $\left(k_{\mathrm{ET}}\right)$ are governed by three parameters (eq 1$):^{8}$ (i) the electronic coupling between the donor and the acceptor, $H_{\mathrm{DA}}$; (ii) the reaction free energy $\left(\Delta G_{\mathrm{ET}}^{0}\right)$; and (iii) the reorganization energy accompanying electron transfer, $\lambda$.

$$
k_{\mathrm{ET}}=\sqrt{\frac{\pi}{\hbar^{2} \lambda k_{\mathrm{B}} T}} H_{\mathrm{DA}}{ }^{2} \exp \left(-\frac{\left(\lambda+\Delta G_{E T}^{0}\right)^{2}}{4 \lambda k_{\mathrm{B}} T}\right)
$$

The last term of eq 1 is often called the "nuclear factor", 9 and it is responsible for the well-known "inverted driving-force effect" which causes $k_{\mathrm{ET}}$ to decrease when $-\Delta G_{\mathrm{ET}}^{0}>\lambda .^{10}$ Distance dependence studies of $k_{\mathrm{ET}}$ often focus on $H_{\mathrm{DA}}$ because the superexchange mediated donor-acceptor coupling is obviously strongly dependent on distance. ${ }^{5 \mathrm{a}, \mathrm{d}, 11}$ However, the reorganization energy, or more precisely its outer-sphere (solvent) contribution $\left(\lambda_{\mathrm{o}}\right)$, can exhibit non-negligible distance dependence as well. ${ }^{12}$ It was noted more than 30 years ago that under certain conditions the distance dependences of $H_{\mathrm{DA}}$ and $\lambda_{\mathrm{o}}$ can counteract each other in such a way that there will be maxima of $k_{\mathrm{ET}}$ at large donor-acceptor distances $\left(r_{\mathrm{DA}}\right) \cdot{ }^{6}$ However, this remained a theoretical prediction until recently. ${ }^{7}$

This prediction was based on the following simple logic. According to eq $1, k_{\mathrm{ET}}$ exhibits a Gaussian free energy dependence, resulting in so-called Marcus parabola when plotting $\ln \left(k_{\mathrm{ET}}\right)$ versus $-\Delta G_{\mathrm{ET}}^{0}$ (Figure 1$) . H_{\mathrm{DA}}$ usually decreases exponentially with increasing $r_{\mathrm{DA}}$, a and since $k_{\mathrm{ET}} \propto$ $H_{\mathrm{DA}}{ }^{2}$ (eq 1), the parabolas in Figure 1 shift downward with increasing $r_{\mathrm{DA}}$. Furthermore, as $r_{\mathrm{DA}}$ increases, $\lambda_{\mathrm{o}}$ increases, ${ }^{8,12,13}$ shifting the parabolas in Figure 1 to the right because maximal $k_{\mathrm{ET}}$ is reached when $-\Delta G_{\mathrm{ET}}^{0}=\lambda$. The net outcome is a shift of the parabolas to the bottom right corner. ${ }^{14}$ From Figure 1 it becomes obvious that there are regimes (for example, at the dotted vertical line) in which $k_{\mathrm{ET}}$ increases with increasing $r_{\mathrm{DA}}$ to reach a maximum at a given distance, and then it decreases at even greater $r_{\mathrm{DA}}$. Earlier studies have demonstrated that the downward right shift of Marcus parabola can lead to weaker distance dependences for strongly exergonic charge-recombination reactions than for less exergonic charge-separation processes, ${ }^{14}$ but to our knowledge there had been no experimental observations of clear-cut electron transfer rate maxima as a function of $r_{\mathrm{DA}}$ prior to our recent communication. ${ }^{7}$ The effect had, however, been invoked as a possible explanation for the difficulties encountered when attempting to observe the inverted driving-force effect in early studies of bimolecular electron transfer. ${ }^{15}$

Received: November 15, 2015

Published: January 22, 2016 


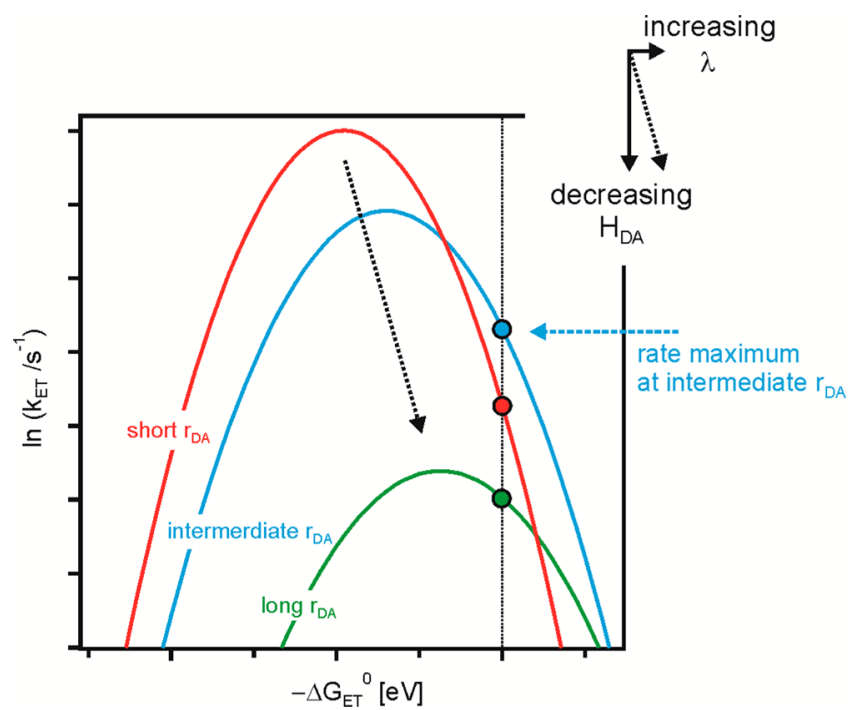

Figure 1. Plot of $\ln \left(k_{\mathrm{ET}}\right)$ vs $-\Delta G_{\mathrm{ET}}^{0}$ showing so-called Marcus parabola. The effect of increasing donor-acceptor distance $\left(r_{\mathrm{DA}}\right)$ on these parabola is illustrated. The dotted vertical line marks a driving force for which $k_{\mathrm{ET}}$ exhibits a maximum at intermediate $r_{\mathrm{DA}}$.

In this paper we report on the distance dependence of $k_{\mathrm{ET}}$ for intramolecular electron transfer from photogenerated anthraquinone radical anions $\left(\mathrm{AQ}^{-}\right)$to triarylamine radical cations $\left(\mathrm{TAA}^{+}\right)$in the three series of triads shown in Scheme 1.

Scheme 1. Molecular Structures of the Three Triad Series and a Reference Compound Investigated in This Work ${ }^{a}$

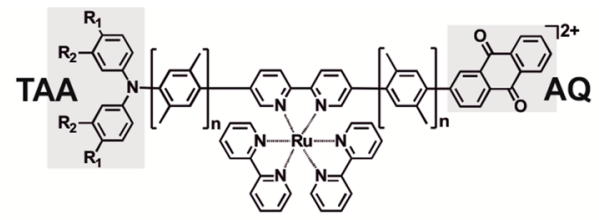

la: $R_{1}=O_{3}, R_{2}=H, n=1 \quad$ lb: $\quad R_{1}=C_{3}, R_{2}=H, n=1 \quad$ lc: $\quad R_{1}=R_{2}=O_{3} H_{3}, n=1$ Ila: $R_{1}=O \mathrm{OCH}_{3}, \mathrm{R}_{2}=\mathrm{H}, \mathrm{n}=2 \quad$ Ilb: $\mathrm{R}_{1}=\mathrm{CH}_{3}, \mathrm{R}_{2}=\mathrm{H}, \mathrm{n}=2 \quad$ Ilc: $\mathrm{R}_{1}=\mathrm{R}_{2}=\mathrm{OCH}_{3}, \mathrm{n}=2$ IIIla: $R_{1}=\mathrm{OCH}_{3}, \mathrm{R}_{2}=\mathrm{H}, \mathrm{n}=3 \quad$ IIIb: $\mathrm{R}_{1}=\mathrm{CH}_{3}, \mathrm{R}_{2}=\mathrm{H}, \mathrm{n}=3 \quad$ IIIc: $\mathrm{R}_{1}=\mathrm{R}_{2}=\mathrm{OCH}_{3}, \mathrm{n}=3$

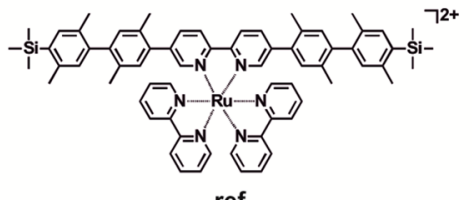

ref

${ }^{a}$ Center-to-center donor-acceptor distances $\left(r_{\mathrm{DA}}\right)$ are $22.0 \AA$ for $n=$ 1, $30.6 \AA$ for $n=2$, and $39.2 \AA$ for $n=3$ according to molecular modeling.

Selective photoexcitation of the central $\mathrm{Ru}(\mathrm{bpy})_{3}{ }^{2+}$ photosensitizer unit (bpy $=2,2^{\prime}$-bipyridine) induced a sequence of intramolecular electron transfer events which resulted in the $\mathrm{AQ}^{-} / \mathrm{TAA}^{+}$radical ion pair in all nine cases. For the ensuing charge-recombination event we observed a rate maximum at large $r_{\mathrm{DA}}(\sim 30.6 \AA)$ in all three triad series. Specifically, $k_{\mathrm{ET}}$ is larger by factors of $6-10$ for the triads with $n=2$ than for the triads with $n=1$ ( $n$ is the number of $p$-xylene spacers on each side of the central bpy ligand). This observation can be rationalized on the basis of the effect outlined above. Our prior communication reported exclusively on triads Ia-IIIa which all bear anisylamine donor groups. By using tolylamine (Ib-IIIb) and veratrylamine (Ic-IIIc) donor groups, we were able to explore the influence of $-\Delta G_{\mathrm{ET}}^{0}$ and $\lambda$ on the distance dependence of $k_{\mathrm{ET}}$. This is important because in the model illustrated by Figure 1 (based on eq 1), the effect of a rate increase with increasing $r_{\mathrm{DA}}$ should depend on the ratio of $-\Delta G_{\mathrm{ET}}^{0}$ and $\lambda$.

\section{RESULTS AND DISCUSSION}

Synthesis. The functionalized ligands of the nine triads from Scheme 1 were synthesized using Pd-catalyzed C-C and $\mathrm{N}-\mathrm{C}$ coupling reactions as described in detail in the Supporting Information. The final triads were characterized by ${ }^{1} \mathrm{H}$ NMR spectroscopy, high-resolution electrospray ionization mass spectrometry, and elemental analysis.

Optical Absorption Properties. UV-vis spectra of the nine triads were recorded in $1: 1(\mathrm{v}: \mathrm{v}) \mathrm{CH}_{3} \mathrm{CN} / \mathrm{H}_{2} \mathrm{O}$ at $20{ }^{\circ} \mathrm{C}$; the results are shown in Figure 2 . In each case, a ${ }^{1}$ MLCT

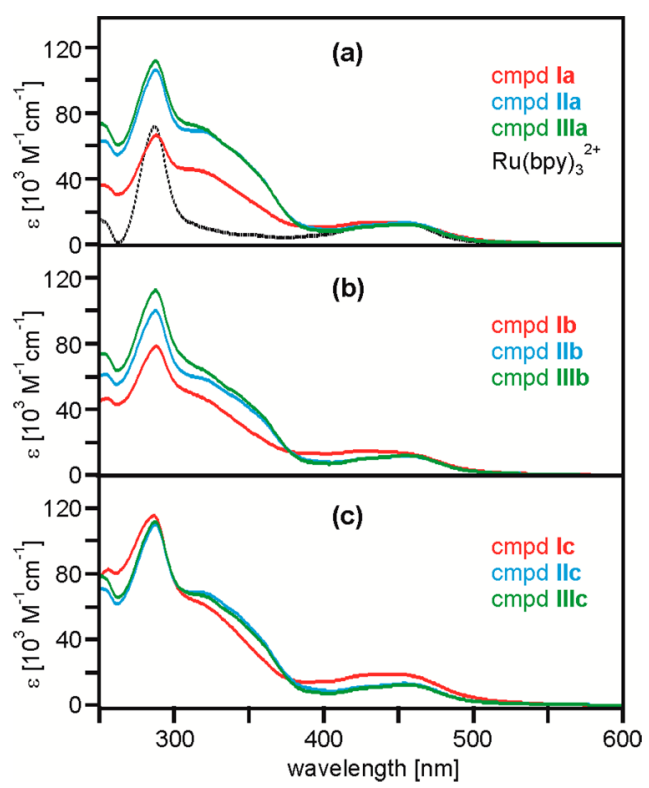

Figure 2. UV-vis spectra of (a) Ia-IIIa, (b) Ib-IIIb, and (c) Ic-IIIc in $1: 1$ (v:v) $\mathrm{CH}_{3} \mathrm{CN} / \mathrm{H}_{2} \mathrm{O}$ at $20{ }^{\circ} \mathrm{C}$. The color code is as in Scheme 1 . Red: shortest member of the series; blue: intermediate member of the series; green: longest member of the series.

absorption band centered around $450 \mathrm{~nm}$ and bpy-localized $\pi-\pi^{*}$ absorptions around $290 \mathrm{~nm}$ are the most prominent features. AQ and TAA related absorptions manifest between 300 and $380 \mathrm{~nm}$, as the comparison with the spectrum of $\mathrm{Ru}(\mathrm{bpy})_{3}{ }^{2+}$ (black dotted trace in Figure 2a) shows. The distance dependences of the UV-vis spectra in Figure 2 are less pronounced than what has been previously observed for $p$ phenylene oligomer structures, ${ }^{3,1,16}$ presumably because the equilibrium torsion angle between adjacent $p$-xylene units is significantly larger than between neighboring $p$-phenylene moieties. $^{17}$

Electrochemical Properties. Cyclic voltammetry was performed in 1:1 (v:v) $\mathrm{CH}_{3} \mathrm{CN} / \mathrm{H}_{2} \mathrm{O}$ and in neat $\mathrm{CH}_{3} \mathrm{CN}$ in order to estimate reaction free energies for electron transfer. The electrochemical potentials for anthraquinone reduction and triarylamine radical cation oxidation are reported in Table 1; the actual voltammograms are in the Supporting Information (Figures S1 and S2). The Weller equation was employed for obtaining the $-\Delta G_{\mathrm{ET}}^{0}$ values in the last two columns of Table $1{ }^{18}$ The main trends are as follows: (i) In all nine triads, 
Table 1. Redox Potentials (in volts vs SCE) for the Terminal Donor and Acceptor Components of the Three Compound Series in 1:1 (v:v) $\mathrm{CH}_{3} \mathrm{CN} / \mathrm{H}_{2} \mathrm{O}$ and in Neat $\mathrm{CH}_{3} \mathrm{CN}$; (Negative) Reaction Free Energies $\left(-\Delta G_{\mathrm{ET}}^{0}\right)$ Associated with Thermal Electron Transfer from $\mathrm{AQ}^{-}$to $\mathrm{TAA}^{+}$Based on These Potentials, Estimated Using the Weller Equation (Using $r_{\mathrm{DA}}$ Values as Defined in the Caption of Scheme 1$)^{18}$

\begin{tabular}{|c|c|c|c|c|c|c|}
\hline & \multicolumn{2}{|c|}{$E^{0}\left(\mathrm{TAA}^{+} / \mathrm{TAA}\right)$} & \multicolumn{2}{|c|}{$E^{0}\left(\mathrm{AQ} / \mathrm{AQ}^{-}\right)$} & \multicolumn{2}{|c|}{$-\Delta G_{\mathrm{ET}}^{0}[\mathrm{eV}]^{a}$} \\
\hline & $\mathrm{CH}_{3} \mathrm{CN} / \mathrm{H}_{2} \mathrm{O}$ & $\mathrm{CH}_{3} \mathrm{CN}$ & $\mathrm{CH}_{3} \mathrm{CN} / \mathrm{H}_{2} \mathrm{O}$ & $\mathrm{CH}_{3} \mathrm{CN}$ & $\mathrm{CH}_{3} \mathrm{CN} / \mathrm{H}_{2} \mathrm{O}$ & $\mathrm{CH}_{3} \mathrm{CN}$ \\
\hline Ia & 0.63 & 0.79 & -0.70 & -0.82 & $1.33 \pm 0.05$ & $1.62 \pm 0.05$ \\
\hline IIa & 0.59 & 0.73 & -0.70 & -0.87 & $1.29 \pm 0.05$ & $1.61 \pm 0.05$ \\
\hline IIIa & 0.58 & 0.72 & -0.65 & -0.89 & $1.23 \pm 0.05$ & $1.62 \pm 0.05$ \\
\hline $\mathrm{Ib}$ & 0.80 & 0.97 & -0.70 & -0.86 & $1.51 \pm 0.05$ & $1.84 \pm 0.05$ \\
\hline IIb & 0.76 & 0.94 & -0.69 & -0.87 & $1.46 \pm 0.05$ & $1.82 \pm 0.05$ \\
\hline IIIb & 0.75 & 0.94 & -0.65 & -0.83 & $1.41 \pm 0.05$ & $1.78 \pm 0.05$ \\
\hline Ic & 0.59 & 0.74 & -0.70 & -0.85 & $1.30 \pm 0.05$ & $1.60 \pm 0.05$ \\
\hline IIc & 0.55 & 0.67 & -0.70 & -0.85 & $1.26 \pm 0.05$ & $1.53 \pm 0.05$ \\
\hline IIII & 0.54 & 0.66 & -0.68 & -0.85 & $1.23 \pm 0.05$ & $1.52 \pm 0.05$ \\
\hline
\end{tabular}

oxidation of TAA and reduction of AQ occurs more readily in 1:1 (v:v) $\mathrm{CH}_{3} \mathrm{CN} / \mathrm{H}_{2} \mathrm{O}$ than in neat $\mathrm{CH}_{3} \mathrm{CN}$, leading to significantly lower driving force for electron transfer from $\mathrm{AQ}^{-}$ to $\mathrm{TAA}^{+}$in the solvent mixture; (ii) electrochemical potentials for oxidation of TAA to $\mathrm{TAA}^{+}\left(E^{0}\left(\mathrm{TAA}^{+} / \mathrm{TAA}\right)\right)$ increase in the order veratrylamine < anisylamine < tolylamine; (iii) $\mathrm{AQ} /$ $\mathrm{AQ}^{-}$redox potentials $\left(E^{0}\left(\mathrm{AQ} / \mathrm{AQ}^{-}\right)\right)$are similar in all nine triads; (iv) within a given triad series and in a given solvent, $\Delta G_{\mathrm{ET}}^{0}$ values are relatively constant. For the most part, these trends are compatible with expectation. Quinone reductions commonly occur more readily in protic solvent due to hydrogen bonding or protonation, ${ }^{19}$ and the AQ units are far away from the TAA donors hence chemical modification of the latter should not affect $A Q$ reduction. The observed order of $\mathrm{TAA}^{+} / \mathrm{TAA}$ redox potentials correlates well with the donor strength of substituents, ${ }^{20}$ although we had anticipated a somewhat greater difference between veratrylamines and anisylamines.

Table 1 lists only the reaction free energies for charge recombination between $\mathrm{AQ}^{-}$and $\operatorname{TAA}^{+}\left(\Delta G_{\mathrm{CR}}^{0}\right)$, but not the reaction free energies for formation of the $\mathrm{AQ}^{-} / \mathrm{TAA}^{+}$radical ion pair out of the initially excited ${ }^{3} \mathrm{MLCT}$ state. The $\mathrm{AQ}^{-} /$ $\mathrm{TAA}^{+}$radical ion pair forms in a sequence of two individual electron transfer steps. In $1: 1(\mathrm{v}: \mathrm{v}) \mathrm{CH}_{3} \mathrm{CN} / \mathrm{H}_{2} \mathrm{O}$, oxidative quenching of ${ }^{3} \mathrm{MLCT}$-excited $\mathrm{Ru}(\text { bpy })_{3}{ }^{2+}$ by $\mathrm{AQ}\left(\Delta G_{\mathrm{ET}}^{0} \approx\right.$ $-0.4 \mathrm{eV}$ in all nine cases) is followed by electron transfer from TAA to $\mathrm{Ru}(\mathrm{bpy}){ }_{3}{ }^{3+}\left(\Delta G_{\mathrm{ET}}^{0}\right.$ varies between -0.2 and $-0.5 \mathrm{eV}$; see Figure $\mathrm{S} 3 \mathrm{a})$. The inverse reaction sequence is less likely because electron transfer from TAA to ${ }^{3}$ MLCT-excited $\mathrm{Ru}(\mathrm{bpy})_{3}{ }^{2+}$ is energetically much less favorable under these conditions $\left(\Delta G_{\mathrm{ET}}^{0}\right.$ ranges from 0.0 to $\left.+0.2 \mathrm{eV}\right)$. A generic energy level scheme is shown in Figure S3a. In neat $\mathrm{CH}_{3} \mathrm{CN}$, the reaction free energy for reductive ${ }^{3} \mathrm{MLCT}$ quenching by TAA varies between 0.0 and $-0.3 \mathrm{eV}$ among the nine triads, whereas for oxidative quenching by $\mathrm{AQ} \Delta G_{\mathrm{ET}}^{0} \approx+0.1 \mathrm{eV}$ for all nine triads (Figure $\mathrm{S} 3 \mathrm{~b}$ ). Thus, the driving forces for the individual photoinduced charge-separation steps become quite small in neat $\mathrm{CH}_{3} \mathrm{CN}$, and the quantum yields for formation of the $\mathrm{AQ}^{-} / \mathrm{TAA}^{+}$radical ion pair are comparatively low. In more apolar solvents the respective driving forces are even lower, and for this reason our investigations focused exclusively on 1:1 (v:v) $\mathrm{CH}_{3} \mathrm{CN} / \mathrm{H}_{2} \mathrm{O}$ and on neat $\mathrm{CH}_{3} \mathrm{CN}$.

Transient Absorption Spectroscopy and Spectroelectrochemistry. The ruthenium(II) chromophore of the triads from Scheme 1 was excited selectively using laser pulses of 532 nm wavelength and $\sim 10$ ns duration. Transient absorption spectra were time-averaged over $200 \mathrm{~ns}$ after the laser pulses, unless otherwise noted. Most of the spectra in Figure 3 were recorded immediately after pulsed excitation, except for those of IIIa, IIIb, IIIb, and IIIc in which the formation of $\mathrm{AQ}^{-} /$ $\mathrm{TAA}^{+}$radical ion pairs is comparatively slow; hence, these spectra were measured with time delays as noted in the figure caption. The spectra in Figure 3 all exhibit three main bands:
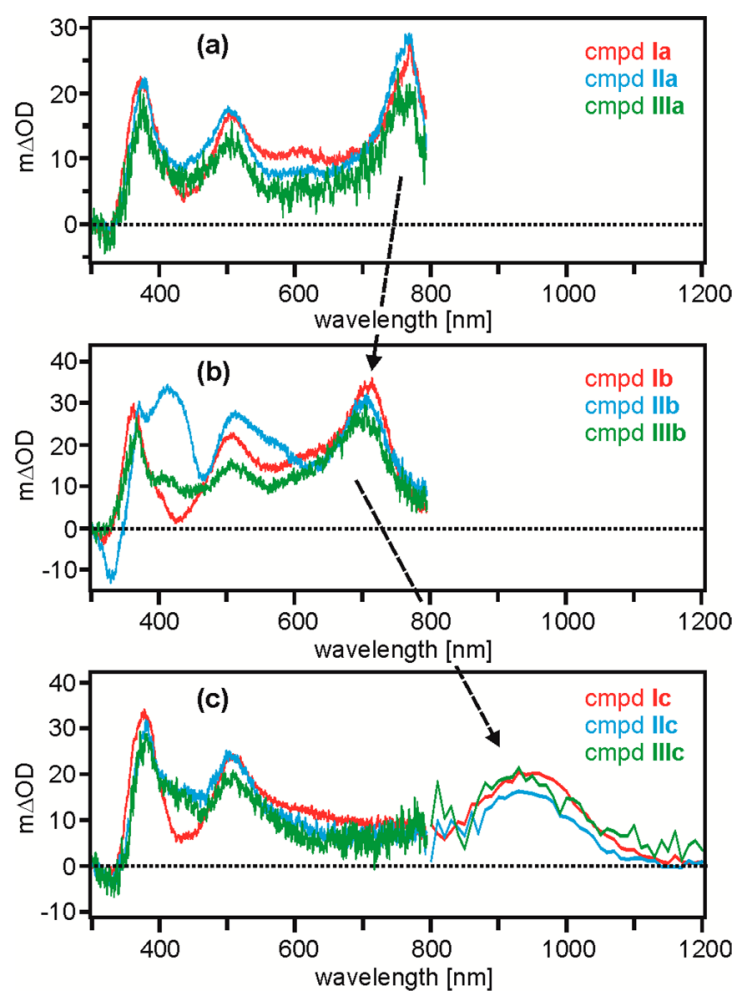

Figure 3. Transient absorption spectra recorded by time integration over $200 \mathrm{~ns}$ after excitation at $532 \mathrm{~nm}$ with laser pulses of $\sim 10 \mathrm{~ns}$ duration: (a) triad series a; (b) triad series b; (c) triad series c. The color code is explained in the insets. Sample concentrations were 20 $\mu \mathrm{M}$ in $1: 1$ (v:v) $\mathrm{CH}_{3} \mathrm{CN} / \mathrm{H}_{2} \mathrm{O}$ at $20{ }^{\circ} \mathrm{C}$ in all cases. Spectra for IIIa, IIb, IIIb, and IIIc were recorded with time delays of $3 \mu \mathrm{s}, 60 \mathrm{~ns}, 10 \mu \mathrm{s}$, and $2 \mu \mathrm{s}$, respectively. All other spectra were recorded immediately after pulsed excitation. The dashed arrow marks the same $\mathrm{TAA}^{+}$ absorption band for different triarylamines. 

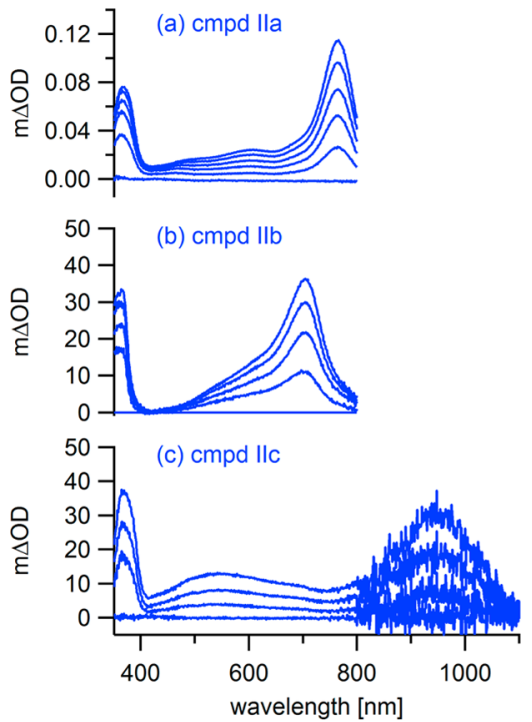

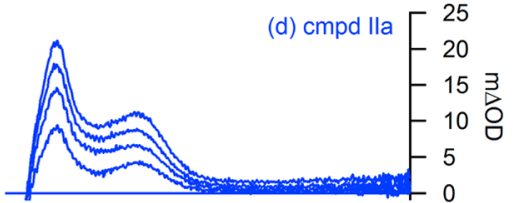

(e) cmpd Ilb
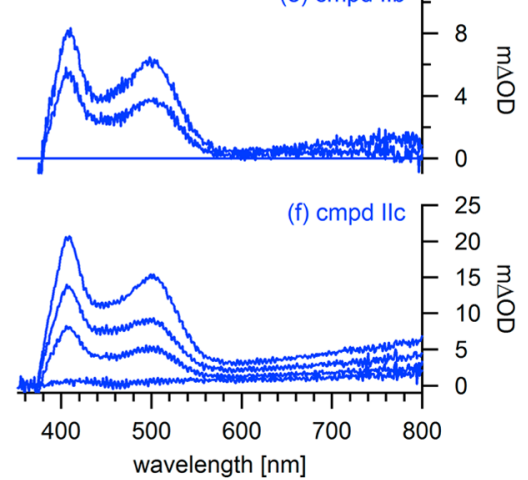

Figure 4. Spectroelectrochemical UV-vis difference spectra recorded for IIa, IIb, and IIc after different time intervals following application of suitable potentials for reduction of $\mathrm{AQ}^{-}$to $\mathrm{AQ}^{-}$(right) and oxidation of TAA to TAA ${ }^{+}$(left). Sample concentrations were $0.1 \mathrm{mM}$ in $1: 1$ (v:v) $\mathrm{CH}_{3} \mathrm{CN} / \mathrm{H}_{2} \mathrm{O}$ at $20{ }^{\circ} \mathrm{C}$ in all cases. The reductive potential was $-0.9 \mathrm{~V}$ vs SCE in all cases; TAA oxidation occurred with potentials of 0.8 (IIa), 1.0 (IIb), and $0.75 \mathrm{~V}$ vs SCE (IIc). Analogous spectroelectrochemical data sets for all other compounds are in the Supporting Information.

one at $370 \mathrm{~nm}$, a second one at $510 \mathrm{~nm}$, and a third band at 770,700 , or $950 \mathrm{~nm}$, depending on which TAA unit is present. Comparison with the spectroelectrochemical data from Figure 4 shows that the three main bands are consistent with the formation of $\mathrm{AQ}^{-} / \mathrm{TAA}^{+}$radical ion pairs. ${ }^{21}$ Figure 4 shows only data for one member out of each triad series; complete spectroelectrochemical data sets are in the Supporting Information (Figures S4-S6).

In the transient absorption spectrum of IIb an additional band at $412 \mathrm{~nm}$ appears (blue trace in Figure $3 \mathrm{~b}$ ). This band is attributed to the ${ }^{3} \mathrm{MLCT}$ excited-state of the ruthenium(II) chromophore, see below.

When recording transient absorption without time delay for IIIa, IIIb, and IIIc, one obtains the spectra shown in Figure 5. The transient absorption spectrum obtained for compound ref (black trace in Figure 5, chemical structure shown in Scheme 1)

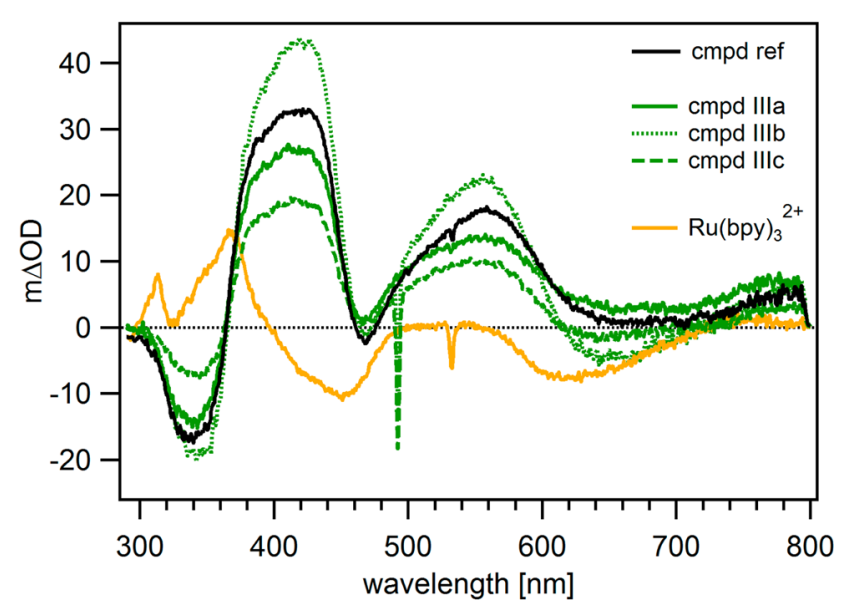

Figure 5. Transient absorption spectra recorded by time integration over $200 \mathrm{~ns}$ after excitation at $532 \mathrm{~nm}$ with laser pulses of $\sim 10 \mathrm{~ns}$ duration. All spectra were measured without time delay. Sample concentrations were $20 \mu \mathrm{M}$ in $1: 1$ (v:v) $\mathrm{CH}_{3} \mathrm{CN} / \mathrm{H}_{2} \mathrm{O}$ at $20{ }^{\circ} \mathrm{C}$ in all cases. is practically identical to the triad spectra in Figure 5. The transient absorptions of ref at 410 and $560 \mathrm{~nm}$ decay with a lifetime of $1400 \mathrm{~ns}$ in $1: 1$ (v:v) $\mathrm{CH}_{3} \mathrm{CN} / \mathrm{H}_{2} \mathrm{O}$ at $20^{\circ} \mathrm{C}$, which is the same as that for the ${ }^{3} \mathrm{MLCT}$ luminescence of ref at $620 \mathrm{~nm}$ (Figure S7). Consequently, the spectra in Figure 5 are attributed to the initially excited ${ }^{3}$ MLCT excited states. The respective spectra are significantly different from the ${ }^{3} \mathrm{MLCT}$ spectrum of $\mathrm{Ru}(\mathrm{bpy})_{3}{ }^{2+}$ (orange trace in Figure 5). Evidently, the $p$-xylene spacers which are attached to the bpy ligand of the triads alter the electronic structure of the photosensitizer units to a non-negligible extent. It seems plausible that there is substantial $\pi$-conjugation between bpy and its adjacent $p$ xylenes.

Electron Transfer Kinetics and Activation Free Energies. Charge recombination between $\mathrm{AQ}^{-}$and $\mathrm{TAA}^{+}$ can be followed by monitoring the temporal evolution of the transient absorption signals at the three maxima observed for each triad in Figure 3. The results from such experiments for all nine triads are shown in Figure 6. The key observations are as follows: (i) For a given triad, essentially identical decay times are extracted from measurements at all three detection wavelengths, indicating that $\mathrm{AQ}^{-}$and $\mathrm{TAA}^{+}$indeed disappear in one reaction step. (ii) Within one compound series, the decay is always fastest for the triad with $n=2$ (red traces). (iii) The decays for the triads with $n=3$ are either biexponential $(a-c, e, g-i)$ or exhibit a rise-and-decay behavior $(d, f)$ on the time scales shown in Figure 6 (green traces).

Rate constants for intramolecular electron transfer from $\mathrm{AQ}^{-}$ to $\mathrm{TAA}^{+}$in the triads with $n=1$ and $n=2$ were determined from single-exponential fits to the decay data in Figure 6, and the results are summarized in Table 2 . The biexponential decays (or rise-and-decay curves) for the triads with $n=3$ result from comparatively slow formation of the $\mathrm{AQ}^{-} / \mathrm{TAA}^{+}$radical ion pairs. The rapid decay (or rise) times observed in the green traces of Figure 6 are caused by disappearance of the initially excited ${ }^{3}$ MLCT state, as proven unambiguously by the transient absorption spectra shown in Figure 5. In most cases (a-c, e, gi), the absorbance of this ${ }^{3} \mathrm{MLCT}$ state at the relevant detection 

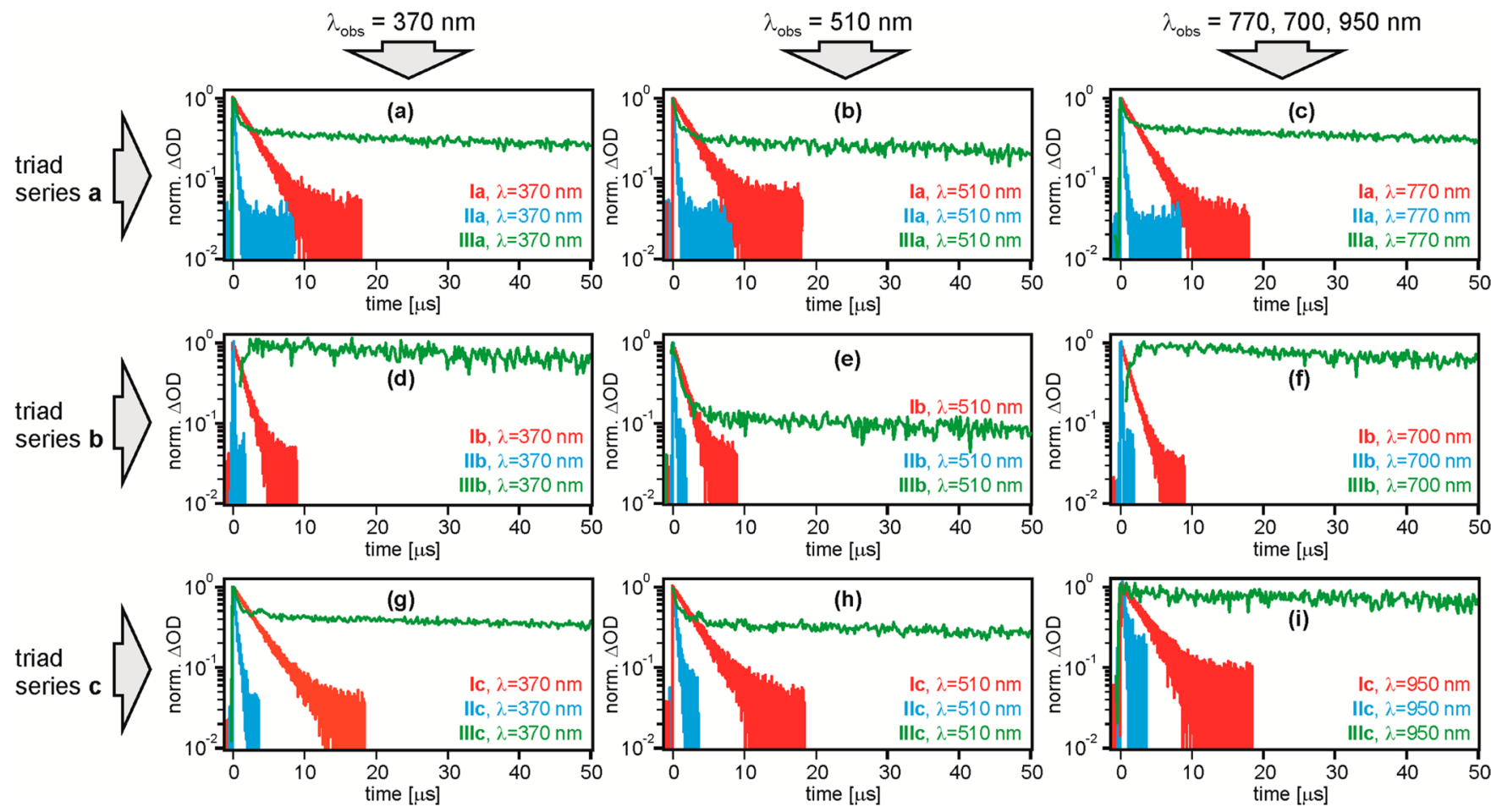

Figure 6. Decays of the transient absorption signals at three different detection wavelengths $(\lambda)$ for all nine triads. Uppermost horizontal line: triad series a, $\lambda=370 \mathrm{~nm}(\mathrm{a}), \lambda=510 \mathrm{~nm}(\mathrm{~b}), \lambda=770 \mathrm{~nm}$ (c). Middle horizontal line: triad series b, $\lambda=370 \mathrm{~nm}(\mathrm{~d}), \lambda=510 \mathrm{~nm}(\mathrm{e}), \lambda=700 \mathrm{~nm}(\mathrm{f})$. Bottom horizontal line: triad series $c, \lambda=370 \mathrm{~nm}(\mathrm{a}), \lambda=510 \mathrm{~nm}(\mathrm{~b}), \lambda=950 \mathrm{~nm}$ (c). The color code is explained in the insets. Sample concentrations were $20 \mu \mathrm{M}$ in $1: 1$ (v:v) $\mathrm{CH}_{3} \mathrm{CN} / \mathrm{H}_{2} \mathrm{O}$ at $20^{\circ} \mathrm{C}$; excitation occurred at $532 \mathrm{~nm}$ with pulses of $\sim 10 \mathrm{~ns}$ duration in all cases. See text for explanation of the fast decay components detected for IIIa, IIIb, and IIIc.

Table 2. Rate Constants $\left(k_{\mathrm{ET}}\right)$ for Thermal Electron Transfer from $\mathrm{AQ}^{-}$to $\mathrm{TAA}^{+}$in the Three Compound Series in 1:1 (v:v) $\mathrm{CH}_{3} \mathrm{CN} / \mathrm{H}_{2} \mathrm{O}$ at $20{ }^{\circ} \mathrm{C}$; Activation Free Energies $\left(\Delta G_{\mathrm{ET}}{ }^{\ddagger}\right)$ Determined from Temperature-Dependence Studies

\begin{tabular}{|c|c|c|c|c|c|c|}
\hline \multirow[b]{2}{*}{ series } & \multicolumn{2}{|c|}{ I } & \multicolumn{2}{|c|}{ II } & \multicolumn{2}{|c|}{ III } \\
\hline & $k_{\mathrm{ET}}\left[\mathrm{s}^{-1}\right]$ & $\Delta G_{\mathrm{ET}}^{\stackrel{\ddagger}{\ddagger}[\mathrm{meV}]}$ & $k_{\mathrm{ET}}\left[\mathrm{s}^{-1}\right]$ & $\Delta G_{\mathrm{ET}} \stackrel{\ddagger}{\ddagger}[\mathrm{meV}]$ & $k_{\mathrm{ET}}\left[\mathrm{s}^{-1}\right]$ & $\Delta G_{\mathrm{ET}}{ }^{*}[\mathrm{meV}]$ \\
\hline a & $(3.58 \pm 0.36) \times 10^{5}$ & $43 \pm 2$ & $(2.87 \pm 0.29) \times 10^{6}$ & $-2 \pm 1$ & $(1.53 \pm 0.15) \times 10^{4}$ & $108 \pm 9$ \\
\hline $\mathrm{b}$ & $(6.90 \pm 0.69) \times 10^{5}$ & $26 \pm 3$ & $(7.41 \pm 0.74) \times 10^{6}$ & $-2 \pm 8$ & $(2.43 \pm 0.24) \times 10^{4}$ & $46 \pm 5$ \\
\hline c & $(3.13 \pm 0.31) \times 10^{5}$ & $41 \pm 1$ & $(2.00 \pm 0.20) \times 10^{6}$ & $-1 \pm 1$ & $(1.34 \pm 0.13) \times 10^{4}$ & $126 \pm 11$ \\
\hline
\end{tabular}

wavelengths is higher than that of the $\mathrm{AQ}^{-} / \mathrm{TAA}^{+}$radical ion pair state, leading to biexponential decays rather than the more intuitively expected rise-and-decay behavior. The slower decay components in the green traces of Figure 6 therefore correspond to the process of interest.

When monitoring transient absorption decays on an even longer time scale for the triads with $n=3$, additional decay components can be discerned. As discussed in our prior communication, ${ }^{7}$ these slow processes are attributable to bimolecular electron transfer reactions, and they are not considered further here. For a detailed discussion we refer to our prior communication. ${ }^{7}$

The key finding from the kinetic studies is that $k_{\mathrm{ET}}$ increases by factors of $6-10$ between the triads with $n=1$ and their congeners with $n=2$, irrespective of which TAA unit is considered. Between the triads with $n=2$ and $n=3, k_{\mathrm{ET}}$ decreases by factors of 149-332. These results are displayed graphically in Figure 7. As noted in the Introduction, an exponential decrease of $k_{\mathrm{ET}}$ with increasing distance is usually observed in the electronic tunneling regime. ${ }^{5}$ When hopping mechanisms become operative, the distance dependence can become significantly shallower, but the common observation is

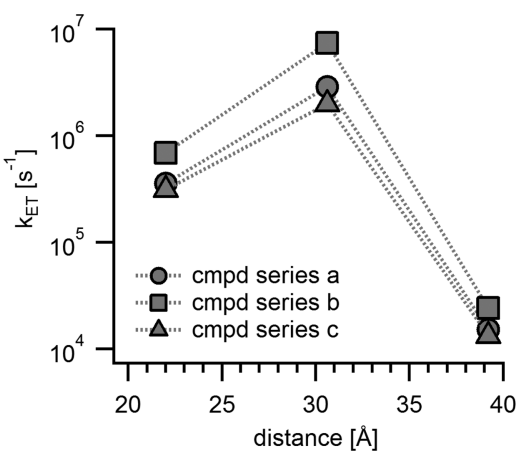

Figure 7. Distance dependence of $k_{\mathrm{ET}}$ in the three triad series.

a decrease of $k_{\mathrm{ET}}$ with increasing $r_{\mathrm{DA}} \cdot{ }^{1 \mathrm{k}, \mathrm{n}, \mathrm{o}, 2,3}$ In this regard the results presented in Figure 7 are highly unusual.

Temperature-dependent measurements of $k_{\mathrm{ET}}$ were performed in order to estimate activation free energies $\left(\Delta G_{\mathrm{ET}}{ }^{\ddagger}\right)$ for electron transfer from $\mathrm{AQ}^{-}$to $\mathrm{TAA}^{+}$in all nine triads. Arrhenius plots based on measurements between 5 and $65{ }^{\circ} \mathrm{C}$ are shown in the Supporting Information (Figure S8); the activation free energies extracted from fits to these plots are summarized in Table 2 (entropy effects were neglected in 
analogy to related studies). ${ }^{3 e, 22}$ We find that in the triads with $n$ $=2$ electron transfer occurs essentially barrierless, whereas for the shorter and longer triads significant activation free energies are required. Thus, the nuclear factor of the semiclassical Marcus equation (last term of eq 1) is particularly favorable for electron transfer in IIa, IIb, and IIc.

Reorganization Energies. Activation free energies and reorganization energies are related to one another by eq $2,{ }^{10 a}$ and consequently $\lambda$ can be estimated based on the $\Delta G_{\mathrm{ET}}{ }^{\ddagger}$ values from Table 2 .

$$
\Delta G_{\mathrm{ET}}^{\ddagger}=\frac{\left(\lambda+\Delta G_{\mathrm{ET}}^{0}\right)^{2}}{4 \lambda}
$$

For the triads with $n=2, \lambda$ must be essentially equal to $-\Delta G_{\mathrm{ET}}^{0}$ because the reaction occurs barrierless in these cases. For the triads with $n=1$ and $n=3$, the quadratic relationship in eq 2 yields two mathematical solutions for $\lambda$, but in each case only one solution is physically meaningful because $\lambda$ is expected to increase with increasing $r_{\mathrm{DA}}{ }^{8,12,13}$ The resulting reorganization energies are summarized in Table 3; they range from values around $1 \mathrm{eV}$ for the shortest triads to values above $2 \mathrm{eV}$ for the longest triads.

Table 3. Reorganization Energies for Thermal Electron Transfer from $\mathrm{AQ}^{-}$to $\mathrm{TAA}^{+}$in the Three Triad Series in 1:1 (v:v) $\mathrm{CH}_{3} \mathrm{CN} / \mathrm{H}_{2} \mathrm{O}$

\begin{tabular}{cccc} 
& \multicolumn{3}{c}{$\lambda[\mathrm{eV}]$} \\
\cline { 2 - 4 } compd series & $\mathrm{I}$ & $\mathrm{II}$ & $\mathrm{III}$ \\
\cline { 2 - 4 } $\mathrm{a}$ & $0.93 \pm 0.35$ & $1.29 \pm 0.05$ & $2.21 \pm 0.28$ \\
$\mathrm{~b}$ & $1.16 \pm 0.38$ & $1.46 \pm 0.05$ & $2.01 \pm 0.29$ \\
$\mathrm{c}$ & $0.91 \pm 0.35$ & $1.26 \pm 0.05$ & $2.31 \pm 0.23$ \\
\hline
\end{tabular}

According to Marcus theory, there is both an inner- and outer-sphere contribution to $\lambda$. Prior work has demonstrated that the inner-sphere contribution $\left(\lambda_{\mathrm{i}}\right)$ in organic compounds can be substantial, ${ }^{23}$ but in principle $\lambda_{\mathrm{i}}$ is expected to be distance-independent. ${ }^{6}$ Simple electrostatic two-sphere (or twoellipsoid) models which treat the solvent as a dielectric continuum are frequently used to describe the distance dependence of the outer-sphere contribution $\left(\lambda_{\mathrm{o}}\right){ }^{8,13}$ It has been noted earlier that these models tend to underestimate the increase of $\lambda_{\mathrm{o}}$ with $r_{\mathrm{DA}}{ }^{12}$ and this is also the case for the triads considered here. ${ }^{7}$ This is not unexpected because the electrostatic models do not take hydrogen bonding into account, but hydrogen bonding between solvent and $\mathrm{AQ}^{-}$is evident from transient absorption spectroscopy. In neat $\mathrm{CH}_{3} \mathrm{CN}$ an $\mathrm{AQ}^{-}$related band is detected at $565 \mathrm{~nm}$ (Figure S9), whereas in 1:1 (v:v) $\mathrm{CH}_{3} \mathrm{CN} / \mathrm{H}_{2} \mathrm{O}$ this band shifts to 510 $\mathrm{nm}$ (Figure 3) as a direct consequence of hydrogen bonding. ${ }^{24}$ On the basis of prior electrochemical studies and on calculations for benzoquinone radical anion, we expect 4-5 $\mathrm{H}_{2} \mathrm{O}$ molecules to be involved in hydrogen bonding to $\mathrm{AQ}^{-} \cdot{ }^{19,25}$ As the distance between $\mathrm{AQ}^{-}$and cationic charges $\left(\mathrm{Ru}(\mathrm{bpy})_{3}{ }^{2+}, \mathrm{TAA}^{+}\right)$gets longer, an increasingly isolated negative charge on $\mathrm{AQ}^{-}$results, making hydrogen bonding stronger with increasing $r_{\mathrm{DA}}$. The net results are large reorganization energies for IIIa, IIIb, and IIIc, but the values in Table 3 are not exceptionally high. For comparison, a prior study reported on reorganization energies around $2 \mathrm{eV}$ for proton-coupled electron transfer (PCET), ${ }^{22}$ and our reaction can be considered a variant of PCET in that several H-bonds are broken upon oxidation of $\mathrm{AQ}^{-26}$

In our prior communication we found that the reorganization energies for triads Ia-IIIa in neat $\mathrm{CH}_{3} \mathrm{CN}$ are in good agreement with predictions made by the above-mentioned electrostatic models. ${ }^{7}$ For instance, for triad IIIa we found $\lambda=$ $1.62 \mathrm{eV}$ by experiment while the simple two-sphere model predicted $1.69 \mathrm{eV}$. For Ib-IIIb analogous investigations in neat $\mathrm{CH}_{3} \mathrm{CN}$ turned out to be impossible because formation of the $\mathrm{AQ}^{-} / \mathrm{TAA}^{+}$radical ion pair is not competitive with other excited-state deactivation pathways due to low driving force (see above). For this reason, the current studies were restricted to $1: 1$ (v:v) $\mathrm{CH}_{3} \mathrm{CN} / \mathrm{H}_{2} \mathrm{O}$.

The reorganization energies for the anisylamine- (series a) and veratrylamine-equipped triads (series c) in $1: 1$ (v:v) $\mathrm{CH}_{3} \mathrm{CN} / \mathrm{H}_{2} \mathrm{O}$ are lower than for the tolylamine-equipped triads (series b), at least for the compounds with $n=1$ (Ia, Ic vs Ib) and $n=2$ (IIa, IIc vs IIb) (Table 3). Possibly, this is due to the less polar nature of the tolylamine, leading to weaker solvent orientation toward the TAA unit prior to photoinduced electron transfer. When combined with strong solvent reorientation in the course of charge separation, thermal charge recombination can then be associated with a higher reorganization energy.

Electronic Coupling. With estimates for $\Delta G_{\mathrm{ET}}^{0}$ and $\lambda$ at hand, the only remaining unknown in eq 1 is the electronic coupling matrix element $H_{\mathrm{DA}}$. Linear regression fits to plots of $\ln \left(k_{\mathrm{ET}} T^{1 / 2}\right)$ versus $T^{-1}$ (Figure S10) were used to determine $H_{\text {DA }}$ for all nine triads; ${ }^{3 e}$ the results are summarized in Table 4.

Table 4. Electronic Coupling between $\mathrm{AQ}^{-}$Donor and $\mathrm{TAA}^{+}$ Acceptor in the Three Triad Series

\begin{tabular}{cccc} 
& \multicolumn{3}{c}{$H_{\mathrm{DA}}\left[\mathrm{cm}^{-1}\right]$} \\
\cline { 2 - 4 } compd series & $\mathrm{I}$ & $\mathrm{II}$ & $\mathrm{III}$ \\
$\mathrm{nyyy}$ a & $0.11 \pm 0.02$ & $0.14 \pm 0.02$ & $0.10 \pm 0.03$ \\
$\mathrm{~b}$ & $0.12 \pm 0.02$ & $0.18 \pm 0.06$ & $0.10 \pm 0.02$ \\
$\mathrm{c}$ & $0.10 \pm 0.02$ & $0.13 \pm 0.03$ & $0.11 \pm 0.02$ \\
\hline
\end{tabular}

In all three triad series we find remarkably weak distance dependences for $H_{\mathrm{DA}}$, which is unexpected in light of prior distance dependence studies of $k_{\mathrm{ET}}$ in oligo- $p$-xylenes and oligo$p$-phenylenes that have produced distance decay constants between 0.4 and $0.8 \AA^{-1}$. $3 \mathrm{~g}, 5 \mathrm{~b}, 16 \mathrm{a}, 17 \mathrm{c}, 27$ However, the earlier $p$ xylene studies focused mostly on weakly exergonic chargeseparation or charge-shift reactions, ${ }^{17,27}$ whereas here more strongly exergonic charge-recombination processes are considered. It has been noted earlier that these two types of processes can exhibit significantly different distance dependences of $H_{\mathrm{DA}}$ because fundamentally different superexchange pathways can be involved. ${ }^{5 b, c, 28}$ Two prior studies have produced evidence for substantially different distance dependences of $k_{\mathrm{ET}}$ for photoinduced charge-separation and thermal charge-recombination events. ${ }^{14,28 \mathrm{a}}$ Moreover, the charge-recombination pathway in our triads involves a $\mathrm{Ru}(\mathrm{bpy})_{3}{ }^{2+}$ unit which can be expected to perturb the electronic structure of the oligo- $p$ xylene "wire" substantially. We suspect that there is significant $\pi$-conjugation between the central bpy ligand and its adjacent $p$-xylene units and that the extent of $\pi$-conjugation increases with increasing chain length. This could explain the weak distance dependence of $H_{\mathrm{DA}}$ in our triads. This interpretation is supported by the transient absorption data in Figure 5 which demonstrate that the electronic structure of the photosensitizer 


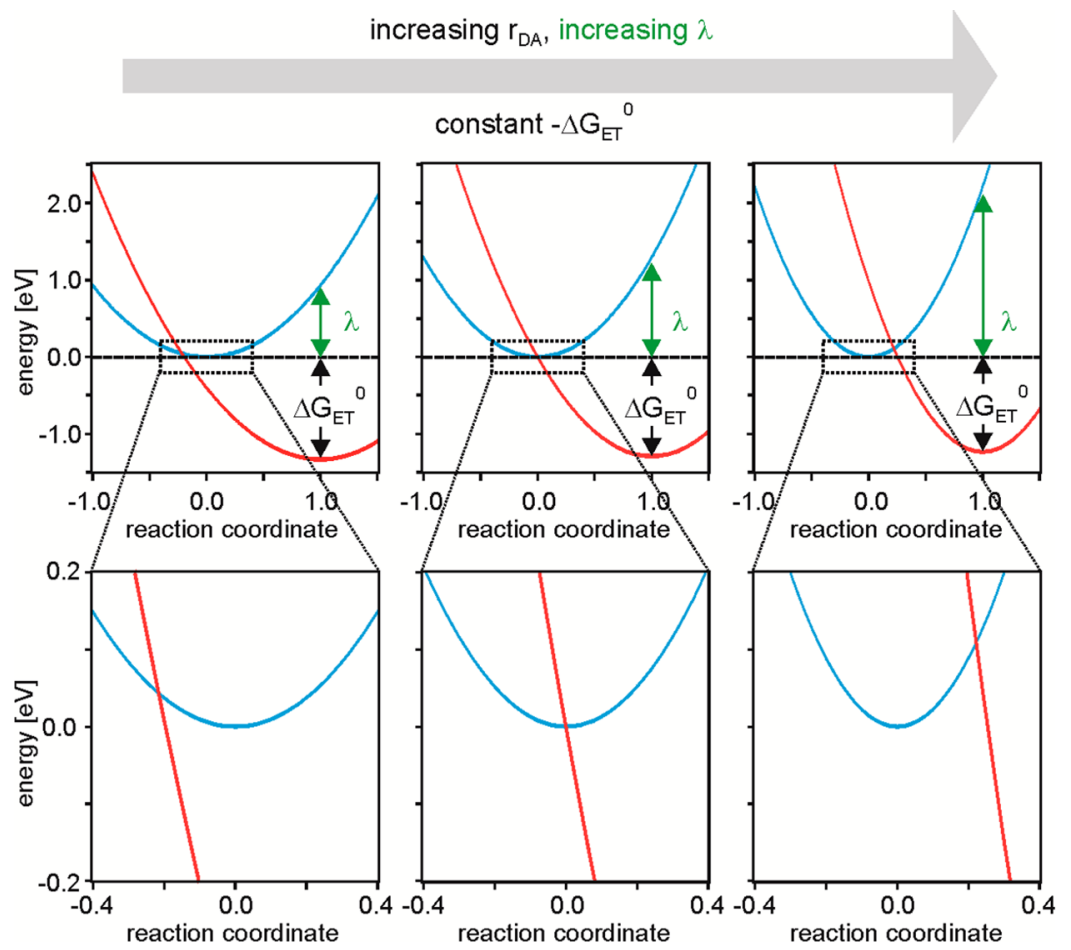

Figure 8. Harmonic potential energy wells for reactant (blue) and product (red) states of charge recombination between $\mathrm{AQ}^{-}$and $\mathrm{TAA}^{+}$in triads Ia (left), IIa (middle), and IIIa (right). The lower half shows zooms of the key regions from the upper half.

unit in IIIa, IIIb, and IIIc is significantly different from that of isolated $\mathrm{Ru}(\mathrm{bpy})_{3}{ }^{2+}$ (green traces versus orange trace).

Interplay of $\lambda$ and $H_{\mathrm{DA}}$. The observation of electron transfer rate maxima at intermediate distances (Figure 7) can be understood on the basis of the combination of weak distance dependences of $H_{\mathrm{DA}}$ and strong distance dependences of $\lambda$. In a simple harmonic potential well model, as $\lambda$ increases with increasing $r_{\mathrm{DA}}$, each of our triad series passes from the inverted (Ia, Ib, Ic) to barrierless (IIa, IIb, IIc) and normal regimes (IIIa, IIIb, IIIc) of electron transfer. Figure 8 illustrates this aspect for the anisylamine series; analogous plots for the tolylamine and veratrylamine series are shown in the Supporting Information (Figures S10 and S11). Such changeovers between different regimes are usually attained through driving-force variation, ${ }^{10}$ but here $\Delta G_{\mathrm{ET}}^{0}$ is nearly constant for a given triad series.

The observation of increasing electron transfer rates with increasing donor-acceptor distance in rigid-rod-like compounds is very rare, ${ }^{3 g, 29}$ and we are unaware of prior studies which have reported clear-cut maxima in $k_{\mathrm{ET}}$ that can be explained by a changeover from inverted to barrierless to normal electron transfer as a function of donor-acceptor distance. Thus, it seems that our triads are the first examples to provide direct evidence for an effect that was predicted more than 30 years ago. ${ }^{6}$

The harmonic potential well model (Figure 8) and the assumption of strictly Gaussian free energy dependences for $k_{\mathrm{ET}}$ (Figure 1) are likely to represent rather crude approximations. Electron-vibration coupling can lead to increased rates in the inverted driving-force regime..$^{3 e, 10 a, 30}$ If, for any reason, electron-vibration coupling would be substantially stronger in the triads with $n=2$ than in those with $n=1$, this could contribute to the experimentally observed increase of $k_{\mathrm{ET}}$ between $n=1$ and $n=2$, as discussed in more detail in our prior communication. ${ }^{7}$ However, the impact of electron- vibration coupling on electron transfer rates is particularly important in the inverted driving-force regime, where it can have an accelerating effect. ${ }^{30}$ We note that in each of our three triad series charge-recombination occurs in the inverted regime only in the shortest member (Ia, Ib, Ic), while in the longer members it is either activationless (IIa, IIb, IIc) or in the normal regime (IIIa, IIIb, IIIc). Thus, if electron-vibration coupling effects are indeed important in our systems, they are likely to accelerate $k_{\mathrm{ET}}$ for the shortest members, thus making the rate increase between the systems with $n=1$ and $n=2$ less important than it would be in the absence of electron-vibration coupling.

At any rate, in the absence of any information on electronvibration coupling it seems reasonable to interpret the experimental observations in the simplest possible model, and this is the one used for Figures 1 and 8 .

Interplay of $-\Delta G_{\mathrm{ET}}^{0}$ and $\lambda$. The reaction free energy and the reorganization energy are mutually independent, but their ratio determines the position of the maxima in the Marcus parabola shown in Figure 1. Consequently, the exact distance dependence of $k_{\mathrm{ET}}$ should depend on the relative magnitudes of $-\Delta G_{\mathrm{ET}}^{0}$ and $\lambda$, in particular in the manner described in the following. ${ }^{6}$ When $-\Delta G_{\mathrm{ET}}^{0}<\lambda$ already at short distances, then $k_{\mathrm{ET}}$ simply decreases with increasing distance. Only when $-\Delta G_{\mathrm{ET}}^{0}>\lambda$ at short $r_{\mathrm{DA}}$ can rate maxima be expected at longer distances. In the simplistic model of Figure 1, the higher the ratio of $-\Delta G_{\mathrm{ET}}^{0}$ and $\lambda$ is the stronger the attainable rate increase with increasing $r_{\mathrm{DA}}$ can become. By changing the TAA moiety from anisylamine to tolylamine and veratrylamine, we aimed to vary $-\Delta G_{\mathrm{ET}}^{0} / \lambda$ in a systematic manner. A sizable change in $-\Delta G_{\mathrm{ET}}^{0}$ was indeed achieved between anisylamine and tolylamine (Table 1). However, the anticipated increase of reaction free energy turns out to be accompanied by an increase of $\lambda$ (at least between Ia and Ib as well as between IIa and IIb, Table 3) that we had not anticipated. The net results are then 
similar $-\Delta G_{\mathrm{ET}}^{0} / \lambda$ ratios along the two triad series, as summarized in Table 5. For the veratrylamines, only small

Table 5. Ratios of (Negative) Reaction Free Energy and Reorganization Energy for Thermal Electron Transfer from $\mathrm{AQ}^{-}$to $\mathrm{TAA}^{+}$in the Three Triad Series in 1:1 (v:v) $\mathrm{CH}_{3} \mathrm{CN} /$ $\mathrm{H}_{2} \mathrm{O}$

\begin{tabular}{cccc} 
& \multicolumn{3}{c}{$-\Delta G_{\mathrm{ET}}^{0} / \lambda$} \\
\cline { 2 - 4 } compd series & $\mathrm{I}$ & $\mathrm{II}$ & $\mathrm{III}$ \\
$\mathrm{nyyy} \mathrm{a}$ & $1.4 \pm 0.5$ & $1.0 \pm 0.1$ & $0.6 \pm 0.1$ \\
$\mathrm{~b}$ & $1.3 \pm 0.4$ & $1.0 \pm 0.1$ & $0.7 \pm 0.2$ \\
$\mathrm{c}$ & $1.4 \pm 0.5$ & $1.0 \pm 0.1$ & $0.5 \pm 0.1$ \\
\hline
\end{tabular}

driving-force changes were effected with respect to the anisylamines, and consequently the $-\Delta G_{\mathrm{ET}}^{0} / \lambda$ ratios remain similar in this case as well. This explains why similar distance dependences for $k_{\mathrm{ET}}$ are observed in all three triad series (Figure 7).

Role of Spin. Photoexcitation of the triads into the ${ }^{1}$ MLCT absorption tail at $532 \mathrm{~nm}$ leads to population of a ${ }^{3} \mathrm{MLCT}$ state after rapid intersystem crossing. ${ }^{31}$ Consequently, the initially formed $\mathrm{AQ}^{-} / \mathrm{TAA}^{+}$radical ion pair is likely to have triplet spin multiplicity as well. On the basis of recent studies of chemically related systems with iridium(III) photosensitizers, one can expect thermal equilibration between singlet and triplet radical ion pair states to be complete within $\sim 50 \mathrm{~ns}^{32}$ The rate for the radical ion pair intersystem crossing does not depend significantly on distance (Einstein-Rosen-Podolsky paradox). ${ }^{33}$ Consequently, we expect that charge recombination between $\mathrm{AQ}^{-}$and $\mathrm{TAA}^{+}$(to yield a singlet ground state) occurs from thermally equilibrated singlet and triplet states in all our triads.

Prior studies have demonstrated that the rate of intersystem crossing in radical ion pair states can be greatly amplified when an externally applied magnetic field $\left(B_{\text {ext }}\right)$ equals twice the spin-spin interaction $(J)$ between the two radicals. ${ }^{3 g, 16,34}$ This has typically been the case when $B_{\text {ext }}$ was on the order of $\sim 100$ $\mathrm{mT}$ for molecules with donor-acceptor distances of about 20 Å. An intriguing question is whether earth's magnetic field (ca. $50 \mu \mathrm{T}$ ) could coincidentally induce an enhancement of intersystem crossing in the triads with $n=2$. In principle, this could indeed account for the observed electron transfer rate maxima, but this is a rather exotic alternative explanation. As noted above, it seems likely that thermal equilibration between singlet and triplet radical ion pair states occurs prior to charge recombination in our systems anyway. As one reviewer pointed out, magnetic field effects would probably require specific orientation of the molecules.

\section{CONCLUSIONS}

The experimental observation of rate maxima for thermal electron transfer from $\mathrm{AQ}^{-}$to $\mathrm{TAA}^{+}$units in all three triad series is compatible with a strong distance dependence of $\lambda$ combined with a weak distance dependence of $H_{\mathrm{DA}}$ as predicted more than 30 years ago. ${ }^{6}$ In the simple model of Figure 8, the net result is a changeover from inverted to barrierless to normal electron transfer as a function of donoracceptor distance. Importantly, this occurs at essentially constant driving force. The increase of $\lambda$ with increasing $r_{\mathrm{DA}}$ is what causes the changeover, in clear contrast to prior drivingforce dependence studies at constant donor-acceptor distance. We have used the simplest possible model for explaining the experimental observations, and there is no need to invoke electron-vibration coupling or spin effects to account for the experimental data, yet we realize that this does not rigorously rule out possible involvement of such effects. However, we also note that the simple model of Figure 8 represents the most intuitive approach to understanding the data in Figure 7. The fact that we have now observed this unusual distance dependence in three series of donor-bridge-acceptor molecules clearly indicates that this is not an isolated phenomenon. Yet, among essentially all prior distance dependence studies of electron transfer rates the results from Figure 7 are highly unusual.

The charge-recombination pathways in our compounds include a $\mathrm{Ru}(\mathrm{bpy})_{3}{ }^{2+}$ unit which seems to perturb the electronic structure of the oligo- $p$-xylene "wire" substantially. There is evidence for significant $\pi$-conjugation between the central bpy ligand and its adjacent $p$-xylene units, and we suspect that this contributes to the weak distance dependence of $H_{\mathrm{DA}}$ in our triads. In combination with a strong increase of the reorganization energy with increasing donor-acceptor separation, observation of the unusual distance dependences of $k_{\mathrm{ET}}$ has become possible. One could of course argue that our results merely represent an academic oddity, but this is clearly not the case, as the following brief argument underscores.

For solar energy conversion, one is interested in fast and efficient photoinduced charge separation and slow, inefficient thermal charge recombination. Photoinduced charge separation usually occurs in the normal regime where $-\Delta G_{\mathrm{ET}}^{0}<\lambda$; hence, in bimolecular reactions this process takes place preferentially when donors (D) and acceptors (A) are in close contact with one another. This is because in the normal regime $k_{\mathrm{ET}}$ simply decreases with increasing donor-acceptor distance (Figure 1). For efficient light-to-chemical energy conversion, it is then desirable that oxidation $\left(\mathrm{D}^{+}\right)$and reduction products $\left(\mathrm{A}^{-}\right)$ diffuse away from each other without undergoing direct charge recombination. However, charge recombination frequently takes place in the inverted driving-force regime. Consequently, a changeover from inverted to barrierless and normal regimes is expected as the reorganization energy increases in the course of increasing distance between $\mathrm{D}^{+}$and $\mathrm{A}^{-}$. This means that $\mathrm{D}^{+}$ and $\mathrm{A}^{-}$must overcome a certain critical separation distance until the rate for the undesired charge-recombination reaction does indeed decrease with increasing $r_{\mathrm{DA}}$. An increase of $k_{\mathrm{ET}}$ with increasing $r_{\mathrm{DA}}$ in the course of diffusion immediately after charge separations can severely limit the overall efficiency of light-to-chemical energy conversion.

\section{ASSOCIATED CONTENT}

\section{Supporting Information}

The Supporting Information is available free of charge on the ACS Publications website at DOI: 10.1021/jacs.5b11953.

Detailed synthetic protocols and product characterization data, additional electrochemical and optical spectroscopic data (PDF)

\section{AUTHOR INFORMATION}

\section{Corresponding Author}

*E-mail oliver.wenger@unibas.ch (O.S.W.).

\section{Notes}

The authors declare no competing financial interest. 


\section{ACKNOWLEDGMENTS}

This research was supported by the Swiss National Science Foundation through Grant 200021_146231/1.

\section{REFERENCES}

(1) (a) Edwards, P. P.; Gray, H. B.; Lodge, M. T. J.; Williams, R. J. P. Angew. Chem., Int. Ed. 2008, 47, 6758. (b) Winkler, J. R.; Gray, H. B. J. Am. Chem. Soc. 2014, 136, 2930. (c) Cordes, M.; Giese, B. Chem. Soc. Rev. 2009, 38, 892. (d) Oevering, H.; Paddon-Row, M. N.; Heppener, M.; Oliver, A. M.; Cotsaris, E.; Verhoeven, J. W.; Hush, N. S. J. Am. Chem. Soc. 1987, 109, 3258. (e) Miller, J. R.; Peeples, J. A.; Schmitt, M. J.; Closs, G. L. J. Am. Chem. Soc. 1982, 104, 6488. (f) Strauch, S.; McLendon, G.; McGuire, M.; Guarr, T. J. Phys. Chem. 1983, 87, 3579. (g) Ponce, A.; Gray, H. B.; Winkler, J. R. J. Am. Chem. Soc. 2000, 122, 8187. (h) Schanze, K. S.; Sauer, K. J. Am. Chem. Soc. 1988, 110, 1180. (i) Serron, S. A.; Aldridge, W. S.; Fleming, C. N.; Danell, R. M.; Baik, M. H.; Sykora, M.; Dattelbaum, D. M.; Meyer, T. J. J. Am. Chem. Soc. 2004, 126, 14506. (j) Indelli, M. T.; Chiorboli, C.; Flamigni, L.; De Cola, L.; Scandola, F. Inorg. Chem. 2007, 46, 5630. (k) O'Hanlon, D. C.; Cohen, B. W.; Moravec, D. B.; Dallinger, R. F.; Hopkins, M. D. J. Am. Chem. Soc. 2014, 136, 3127. (1) Meylemans, H. A.; Lei, C. F.; Damrauer, N. H. Inorg. Chem. 2008, 47, 4060. (m) Montes, V. A.; Perez-Bolivar, C.; Agarwal, N.; Shinar, J.; Anzenbacher, P. J. Am. Chem. Soc. 2006, 128, 12436. (n) Lukacs, A.; Eker, A. P. M.; Byrdin, M.; Brettel, K.; Vos, M. H. J. Am. Chem. Soc. 2008, 130, 14394. (o) Moser, C. C.; Keske, J. M.; Warncke, K.; Farid, R. S.; Dutton, P. L. Nature 1992, 355, 796.

(2) (a) Shih, C.; Museth, A. K.; Abrahamsson, M.; Blanco-Rodriguez, A. M.; Di Bilio, A. J.; Sudhamsu, J.; Crane, B. R.; Ronayne, K. L.; Towrie, M.; Vlček, A.; Richards, J. H.; Winkler, J. R.; Gray, H. B. Science 2008, 320, 1760. (b) De Vault, D.; Chance, B. Biophys. J. 1966, 6, 825. (c) Gray, H. B.; Winkler, J. R. Annu. Rev. Biochem. 1996, 65, 537. (d) Genereux, J. C.; Barton, J. K. Chem. Rev. 2010, 110, 1642. (e) Lewis, F. D.; Letsinger, R. L.; Wasielewski, M. R. Acc. Chem. Res. 2001, 34, 159. (f) Giese, B. Acc. Chem. Res. 2000, 33, 631. (g) Schuster, G. B. Acc. Chem. Res. 2000, 33, 253. (h) Wasielewski, M. R. Chem. Rev. 1992, 92, 435 .

(3) (a) Davis, W. B.; Svec, W. A.; Ratner, M. A.; Wasielewski, M. R. Nature 1998, 396, 60. (b) Goldsmith, R. H.; Sinks, L. E.; Kelley, R. F.; Betzen, L. J.; Liu, W. H.; Weiss, E. A.; Ratner, M. A.; Wasielewski, M. R. Proc. Natl. Acad. Sci. U. S. A. 2005, 102, 3540. (c) Giacalone, F.; Segura, J. L.; Martín, N.; Guldi, D. M. J. Am. Chem. Soc. 2004, 126, 5340. (d) Harriman, A.; Ziessel, R. Chem. Commun. 1996, 1707. (e) Sukegawa, J.; Schubert, C.; Zhu, X. Z.; Tsuji, H.; Guldi, D. M.; Nakamura, E. Nat. Chem. 2014, 6, 899. (f) Linton, K. E.; Fox, M. A.; Palsson, L. O.; Bryce, M. R. Chem. - Eur. J. 2015, 21, 3997. (g) Weiss, E. A.; Ahrens, M. J.; Sinks, L. E.; Gusev, A. V.; Ratner, M. A.; Wasielewski, M. R. J. Am. Chem. Soc. 2004, 126, 5577. (h) Launay, J.-P. Chem. Soc. Rev. 2001, 30, 386. (i) Lloveras, V.; Vidal-Gancedo, J.; Figueira-Duarte, T. M.; Nierengarten, J. F.; Novoa, J. J.; Mota, F.; Ventosa, N.; Rovira, C.; Veciana, J. J. Am. Chem. Soc. 2011, 133, 5818. (j) Jones, S. C.; Coropceanu, V.; Barlow, S.; Kinnibrugh, T.; Timofeeva, T.; Brédas, J. L.; Marder, S. R. J. Am. Chem. Soc. 2004, 126, 11782. (k) Zhu, Y. B.; Wolf, M. O. J. Am. Chem. Soc. 2000, 122, 10121. (1) Welter, S.; Lafolet, F.; Cecchetto, E.; Vergeer, F.; De Cola, L. ChemPhysChem 2005, 6, 2417. (m) Barlow, S.; Risko, C.; Chung, S. J.; Tucker, N. M.; Coropceanu, V.; Jones, S. C.; Levi, Z.; Brédas, J. L.; Marder, S. R. J. Am. Chem. Soc. 2005, 127, 16900.

(4) (a) Onuchic, J. N.; Beratan, D. N.; Winkler, J. R.; Gray, H. B. Annu. Rev. Biophys. Biomol. Struct. 1992, 21, 349. (b) Kumar, K.; Kurnikov, I. V.; Beratan, D. N.; Waldeck, D. H.; Zimmt, M. B. J. Phys. Chem. A 1998, 102, 5529. (c) Newton, M. D. Chem. Rev. 1991, 91, 767.

(5) (a) Gray, H. B.; Winkler, J. R. Proc. Natl. Acad. Sci. U. S. A. 2005, 102, 3534. (b) Wenger, O. S. Acc. Chem. Res. 2011, 44, 25. (c) Eng, M. P.; Albinsson, B. Angew. Chem., Int. Ed. 2006, 45, 5626. (d) Albinsson, B.; Eng, M. P.; Pettersson, K.; Winters, M. U. Phys. Chem. Chem. Phys. 2007, 9, 5847.
(6) Brunschwig, B. S.; Ehrenson, S.; Sutin, N. J. Am. Chem. Soc. 1984, $106,6858$.

(7) Kuss-Petermann, M.; Wenger, O. S. Angew. Chem., Int. Ed. 2016, 55,815 .

(8) Marcus, R. A.; Sutin, N. Biochim. Biophys. Acta, Rev. Bioenerg. 1985, 811, 265.

(9) Sutin, N. Acc. Chem. Res. 1982, 15, 275.

(10) (a) Closs, G. L.; Miller, J. R. Science 1988, 240, 440. (b) Fox, L. S.; Kozik, M.; Winkler, J. R.; Gray, H. B. Science 1990, 247, 1069. (c) Wasielewski, M. R.; Niemczyk, M. P.; Svec, W. A.; Pewitt, E. B. J. Am. Chem. Soc. 1985, 107, 1080.

(11) (a) McConnell, H. M. J. Chem. Phys. 1961, 35, 508. (b) Eng, M. P.; Albinsson, B. Chem. Phys. 2009, 357, 132.

(12) Isied, S. S.; Vassilian, A.; Wishart, J. F.; Creutz, C.; Schwarz, H. A.; Sutin, N. J. Am. Chem. Soc. 1988, 110, 635.

(13) Kirkwood, J. G.; Westheimer, F. H. J. Chem. Phys. 1938, 6, 506.

(14) Yonemoto, E. H.; Saupe, G. B.; Schmehl, R. H.; Hubig, S. M.; Riley, R. L.; Iverson, B. L.; Mallouk, T. E. J. Am. Chem. Soc. 1994, 116, 4786.

(15) Tachiya, M.; Murata, S. J. Phys. Chem. 1992, 96, 8441.

(16) (a) Weiss, E. A.; Tauber, M. J.; Kelley, R. F.; Ahrens, M. J.; Ratner, M. A.; Wasielewski, M. R. J. Am. Chem. Soc. 2005, 127, 11842. (b) Schlicke, B.; Belser, P.; De Cola, L.; Sabbioni, E.; Balzani, V. J. Am. Chem. Soc. 1999, 121, 4207.

(17) (a) Benniston, A. C.; Harriman, A. Chem. Soc. Rev. 2006, 35, 169. (b) Lörtscher, E.; Elbing, M.; Tschudy, M.; von Hänisch, C.; Weber, H. B.; Mayor, M.; Riel, H. ChemPhysChem 2008, 9, 2252. (c) Hanss, D.; Walther, M. E.; Wenger, O. S. Coord. Chem. Rev. 2010, 254, 2584. (d) Helms, A.; Heiler, D.; McLendon, G. J. Am. Chem. Soc. 1991, 113, 4325 .

(18) Weller, A. Z. Phys. Chem. 1982, 133, 93.

(19) (a) Quan, M.; Sanchez, D.; Wasylkiw, M. F.; Smith, D. K. J. Am. Chem. Soc. 2007, 129, 12847. (b) Gupta, N.; Linschitz, H. J. Am. Chem. Soc. 1997, 119, 6384.

(20) (a) Hagopian, L.; Köhler, G.; Walter, R. I. J. Phys. Chem. 1967, 71, 2290. (b) Wu, X.; Davis, A. P.; Lambert, P. C.; Steffen, L. K.; Toy, O.; Fry, A. J. Tetrahedron 2009, 65, 2408.

(21) (a) Hankache, J.; Wenger, O. S. Chem. Commun. 2011, 47, 10145. (b) Hankache, J.; Niemi, M.; Lemmetyinen, H.; Wenger, O. S. Inorg. Chem. 2012, 51, 6333. (c) Lopéz, R.; Leiva, A. M.; Zuloaga, F.; Loeb, B.; Norambuena, E.; Omberg, K. M.; Schoonover, J. R.; Striplin, D.; Devenney, M.; Meyer, T. J. Inorg. Chem. 1999, 38, 2924. (d) Mecklenburg, S. L.; McCafferty, D. G.; Schoonover, J. R.; Peek, B. M.; Erickson, B. W.; Meyer, T. J. Inorg. Chem. 1994, 33, 2974.

(22) Sjödin, M.; Styring, S.; Åkermark, B.; Sun, L. C.; Hammarström, L. J. Am. Chem. Soc. 2000, 122, 3932.

(23) (a) Nelsen, S. F.; Chang, H.; Wolff, J. J.; Adamus, J. J. Am. Chem. Soc. 1993, 115, 12276. (b) Nelsen, S. F.; Ismagilov, R. F.; Powell, D. R. J. Am. Chem. Soc. 1996, 118, 6313. (c) Nelsen, S. F.; Blackstock, S. C.; Kim, Y. J. Am. Chem. Soc. 1987, 109, 677.

(24) (a) Hulme, B. E.; Phillips, G. O.; Land, E. J. J. Chem. Soc., Faraday Trans. 1 1972, 68, 1992. (b) Hankache, J.; Niemi, M.; Lemmetyinen, H.; Wenger, O. S. J. Phys. Chem. A 2012, 116, 8159.

(25) Sinnecker, S.; Reijerse, E.; Neese, F.; Lubitz, W. J. Am. Chem. Soc. 2004, 126, 3280.

(26) Yago, T.; Gohdo, M.; Wakasa, M. J. Phys. Chem. B 2010, 114, 2476.

(27) (a) Wenger, O. S.; Leigh, B. S.; Villahermosa, R. M.; Gray, H. B.; Winkler, J. R. Science 2005, 307, 99. (b) Hanss, D.; Wenger, O. S. Inorg. Chem. 2008, 47, 9081. (c) Hanss, D.; Wenger, O. S. Inorg. Chem. 2009, 48, 671. (d) Hanss, D.; Wenger, O. S. Eur. J. Inorg. Chem. 2009, 3778.

(28) (a) Wiberg, J.; Guo, L. J.; Pettersson, K.; Nilsson, D.; Ljungdahl, T.; Mårtensson, J.; Albinsson, B. J. Am. Chem. Soc. 2007, 129, 155. (b) Pettersson, K.; Wiberg, J.; Ljungdahl, T.; Mårtensson, J.; Albinsson, B. J. Phys. Chem. A 2006, 110, 319. (c) Natali, M.; Campagna, S.; Scandola, F. Chem. Soc. Rev. 2014, 43, 4005. (d) Arrigo, A.; Santoro, A.; Puntoriero, F.; Lainé, P. P.; Campagna, S. Coord. Chem. Rev. 2015, 304, 109. 
(29) Stangel, C.; Schubert, C.; Kuhri, S.; Rotas, G.; Margraf, J. T.; Regulska, E.; Clark, T.; Torres, T.; Tagmatarchis, N.; Coutsolelos, A. G.; Guldi, D. M. Nanoscale 2015, 7, 2597.

(30) (a) Barbara, P. F.; Meyer, T. J.; Ratner, M. A. J. Phys. Chem. 1996, 100, 13148. (b) Jortner, J. J. Chem. Phys. 1976, 64, 4860.

(31) (a) Damrauer, N. H.; Cerullo, G.; Yeh, A.; Boussie, T. R.; Shank, C. V.; McCusker, J. K. Science 1997, 275, 54. (b) McCusker, J. K. Acc. Chem. Res. 2003, 36, 876.

(32) Klein, J. H.; Schmidt, D.; Steiner, U. E.; Lambert, C. J. Am. Chem. Soc. 2015, 137, 11011.

(33) Bohm, D.; Aharonov, Y. Phys. Rev. 1957, 108, 1070.

(34) Colvin, M. T.; Ricks, A. B.; Scott, A. M.; Smeigh, A. L.; Carmieli, R.; Miura, T.; Wasielewski, M. R. J. Am. Chem. Soc. 2011, 133, 1240. 